\title{
EFFECTS OF BENZODIAZEPINES ON PSYCHOMOTOR PERFORMANCE
}

\author{
J.R. WITTENBORN \\ Rutgers University, New Brunswick, New Jersey
}

1 The literature relating to the effects of benzodiazepines on psychomotor performance is critically reviewed.

2 The multiple and diverse psychomotor tests used are assessed according to their ability to demonstrate differences between drugs.

3 Three general conclusions are: (1) The speed with which simple acts of a repetitive nature are performed may be impaired by benzodiazepines. (2) learning and immediate memory will also be impaired. (3) there is relatively little indication that well established higher mental faculties are adversely involved.

OuR interest in the substantive nature of psychomotor effects of psychotropic substances cannot escape the burdens of methodological caveats. An illness may be expressed in disturbances of the psychomotor aspects of behaviour, and a therapeutic substance may modify psychomotor behaviour as an indirect consequence of its therapeutic action. A substance may also have a direct effect on psychomotor behaviour. Indirect consequences of therapeutic effect cannot be distinguished from direct psychomotor effects, and patients are not an appropriate sample for examining psychomotor effects per se. In clinical investigations as in other researches, ambiguity must be eliminated, and obvious sources of confounding must be minimized or discounted statistically. The assessment procedures for the anticipated effects must be pertinent, and they must be carried out in a reliable manner.

Drug-induced behavioural changes may, over time, be influenced also by metabolic adaptations to the substance and by psychological adaptations, including learning to adjust to the primary behavioural consequences of the drug. For these reasons, the subjects examined to show psychomotor effects should be relatively inexperienced with the class of drug under scrutiny. Thus, immediate psychomotor changes, for example, changes during the first day of medication, are assumed to be less subject to ambiguous interpretation than behaviour assessed after repeated administrations of the drug, for example, over a course of treatment. It is proposed, therefore, that optimal subjects for assessing the psychomotor effects per se of benzodiazepines would be normal volunteers assessed in a manner to reflect initial response to the substance.

The design of such inquiries should provide for the standard comparison between premedication behavioural assessments and assessments at fixed intervals during a standard period, for example, through the course of a day of administration of the drug as commonly used in a therapeutic context. It would seem, moreover, that showing the significance of change following the administration of the drug or the character of the response curve is not sufficient, because such changes can result from learning and other irrelevant factors, including the average diurnal variation in level of interest and activity. To be of value therefore, the change that occurs among those receiving the substance in question must be compared with the respective change occurring among others receiving some standard substance, preferably an inert placebo. In most behavioural respects humans tend to be much more variable from individual to individual than laboratory animals. For this reason relatively large samples are particularly desirable for testing behavioural responses to psychotropic substances.

These various $a$ priori comments on the conditions in which a statement of behavioural response to a psychotropic substance is meaningful can serve as criteria for selecting literature to be considered in a review of the effect of benzodiazepines on psychomotor behaviour.

A review of the present topic is embarrassed by the fact that different investigators have used different assessment procedures to show behavioural consequences of benzodiazepines. We are not always justified in generalizing an effect observed with one psychomotor test to results observed with some other equally defensible test. For this reason the results of the many published accounts have not generated a substantial body of mutually confirming implications.

There are numerous benzodiazepines now in therapeutic use or being prepared for such use. For this reason the effect of each psychotropic substance relative to placebo does not exhaust our interest. In any given respect, it is of interest also to compare the effects of each important benzodiazepine with that of every other one. Unfortunately, comprehensive 
systematic programmes of inter-benzodiazepine comparisons are not described in the research literature.

In his review of anxiolytic drugs, McNair (1972) found no consistent indications in the available literature on psychomotor effects. He suggests 'One could, with about equal justification, conclude that mild tranquillizers have little effect on human performance, or that little is known about their effect on human performance, or both'.

Wittenborn (1978) reviewed the behavioural effects of psychotropic drugs in normal humans. In 31 studies providing a placebo group, $49 \mathrm{spec}$ ific comparisons involved an anxiolytic drug. In $55 \%$ of these comparisons, there was no significant contrast, $37 \%$ showed a statistically significant loss in performance and $8 \%$ showed a significant gain. The literature provided no basis for generalizations suffcient to support conceptualizations (as contrasted with descriptions) concerning the broad nature and extent of the behaviour changes in consequence of various psychotropic substances.

The present review is limited to the psychomotor effects of psychotropic drugs of the benzodiazepine class and is further limited to a description of psychomotor effects in non-patient samples where at least eight subjects are available for each treatment under comparison.

Studies describing the psychomotor effects of chlordiazepoxide during the initial day of administration to normal subjects indicate a positive relationship between magnitude of effect and dosage level. This positive relationship is general for benzodiazepines. Ideström \& Cadenius (1963) used choice reaction time, tapping speed, critical flicker fusion frequency, hand coordination, standing steadiness and auditory perception in their comparison of chlordiazepoxide 20 and $40 \mathrm{mg}$. In the sample of 21 male student volunteers, no significant placebo contrasts were found for the $20 \mathrm{mg}$ dosage, but for the $40 \mathrm{mg}$ dosage flicker fusion was decreased. There were significant dosage level contrasts in reaction time, tapping speed and flicker fusion frequency. Holmberg \& WilliamOllson (1963) examined the effect of chlordiazepoxide $60 \mathrm{mg}$. Their sample comprised 20 young female staff members. Two of the six criteria of psychomotor effect changed significantly relative to placebo. Critical flicker fusion frequency was reduced and body sway was reduced.

Hughes et al. (1965) found chlordiazepoxide (15 $\mathrm{mg}$ daily) to have no effect on their sample of 18 graduate students. Although the dosage implications of this finding are consistent with the trends suggested by the studies of Idestrom \& Cadenius (1963) and of Holmberg \& William-Olsson (1963), it should be noted that they did not use the same criteria of psychomotor effect.

Betts et al. (1972) compared the effect of placebo with chlordiazepoxide $50 \mathrm{mg}$ taken over $36 \mathrm{~h}$ in $10 \mathrm{mg}$ units. Drug effect was assessed in terms of perfor- mance in standard tests of driving behind the wheel of an automobile. In the male subjects, chlordiazepoxide had the effect of increasing the time required to complete the test, and the female subjects became less accurate in their steering. As the drug was selfadministered and a span of $36 \mathrm{~h}$ was involved, the results involve uncertainties.

Wittenborn et al. (1976) compared chlordiazepoxide with placebo from the standpoint of changes in pursuit rotor, cancellation, reaction time and time estimation. There were 20 male volunteers in each treatment group. Chlordiazepoxide $30 \mathrm{mg}$ was administered in $10-\mathrm{mg}$ units every $3.5 \mathrm{~h}$ with the first unit administered after early morning pretesting and the third unit administered by mid-afternoon. The assessment battery was repeated in the standard manner at hourly intervals. No clear indication of behaviour impairment was obtained with this divided dosage schedule but, paradoxically, it was found that chlordiazepoxide tended to correct or eliminate a natural tendency to overestimate the duration of temporal intervals.

Smith \& Misiak (1976) reviewed the literature reporting the use of critical flicker fusion frequency in non-psychiatric subjects. No effect was reported for studies where the chlordiazepoxide dosage was $20 \mathrm{mg}$ or less, but in the studies where the dosage was higher chlordiazepoxide had the effect of reducing the critical flicker fusion frequency.

The placebo-controlled studies of diazepam effect on psychomotor responses of normal volunteers are numerous and varied. Whereas only five chlordiazepoxide studies were available for the present review, eleven diazepam studies met the criteria for inclusion. Hughes et al. (1965) compared diazepam with placebo in the cross-over study involving 18 volunteers. A diversified set of psychomotor tests was applied (some with auditory feedback) but none of them showed a significant contrast for the small dose of $6 \mathrm{mg}$ diazepam.

Masuda \& Bakker (1966) reported significant differences between diazepam and placebo on galvanic skin response and written mathematics tests carried out in two conditions; one in the presence of noise and shock and the other without these distractions. The skin resistance was raised with diazepam, and mathematics performance was reduced. Half of the group of 30 patients received diazepam $10 \mathrm{mg}$ and half $20 \mathrm{mg}$. The tests were carried out within $2 \mathrm{~h}$ after ingestion.

Clarke et al. (1970) administered intravenous diazepam in the amount of $0.24 \mathrm{mg} / \mathrm{kg}$ to a randomly selected half of his sample of 12 young volunteers. (The only exception to the requirements of eight or more subjects). In these conditions, for at least $10 \mathrm{~min}$ after injection of diazepam, there was marked anterograde amnesia which was followed by persistent but improving memory impairment. This memory deficit was not attributed to any impairment of consciousness. 
Jäättelä et al. (1971) compared a single dose of diazepam $10 \mathrm{mg}$ with placebo. There were 90 volunteers in each treatment group. Psychomotor effects were measured in terms of Digit Symbol Substitution Test (DSST) and the number series test. Estimations of alertness and motility were also provided. Relative to placebo there was a conspicuous and highly significant impairment of DSST performance, and repeating numbers forward was also impaired. In addition there were significant reductions in physical activity.

Ghoneim et al. (1975) used ten young volunteers to compare diazepam (both 10 and $20 \mathrm{mg}$ ) and placebo in a kind of cross-over procedure. They found that two hours after intravenous administration both dosage levels of diazepam reduced Digit Span relative to placebo. Other losses in performance subsequent to diazepam were tapping speed, serial learning and delayed recall. Diazepam also increased the variability of reaction time. Most of these significant effects occurred after an interval of $2 \mathrm{~h}$, with a tendency for response qualities to approach the premedication level after 6 hours.

Ghoneim \& Mewaldt (1975) compared diazepam $20 \mathrm{mg}$ with placebo. A total of 36 healthy volunteers was available for a cross-over inquiry which provided for the intramuscular administration of diazepam 20 $\mathrm{mg}$ or placebo. Thirty-five minutes after medication there were no differences in the recall of words learned before the drug. When material was learned $90 \mathrm{~min}$ after administration, both immediate and delayed recall were significantly impaired for subjects receiving diazepam. For material presented $2.5 \mathrm{~h}$ after administration there was no significant difference in immediate recall, but for delayed recall of this material the loss for diazepam was significant relative to placebo. Thus, the implications of other trials of memory effects (for example, Clarke et al., 1970) are confirmed and it is apparent that therapeutic doses of diazepam impair memory function.

Kleinknecht \& Donaldson (1975) reviewed the literature describing psychomotor effects of diazepam. Of the 22 studies cited, only two were based on psychiatric populations. The authors classified the many tests represented and on this basis offered some generalizations. It was concluded that the performances classed as reflex speed, including reaction time and tapping, were not considered to be adversely affected by therapeutic levels of diazepam. Critical flicker fusion frequency seemed to be sensitive to diazepam, and in the literature the reduction in fusion frequency was general. Various performances involving decision-making showed indications of a doserelated response; two studies using diazepam $10 \mathrm{mg}$ showed no effect, whereas two studies based on $20 \mathrm{mg}$ reported an effect. Three studies of learning and memory were reviewed. Because of the dissimilarity of the task involved, concluding statements were not offered with confidence. It was suggested, however, that the deficit may be in the consolidation process rather than in short-term memory per se. In the test class identified as concentration and vigilance, letter cancellation was found to be adversely affected at dosages ranging from $10-20 \mathrm{mg}$ but the DSST (despite the sensitivity to benzodiazepines noted in the present review and to tricyclics, such as imipramine; Wittenborn et al., 1976) was not reported to be consistently affected. Such operations as tracing and various motor skills, including pursuit rotor, were classified by these reviewers as perceptual-motor. Tracing was slowed in response to diazepam but there seemed to be no predictable increase in error. Various tests of hand-eye coordination gave varying results and the implications remain uncertain. There was a confirmable disturbance of saccadic eye movements with an increased duration of fixation. Time estimation and awareness of deficit were found to be adversely affected.

Karniol et al. (1976) examined the effect of approximately $5 \mathrm{mg}$ diazepam on tapping and symbol copying tests. No placebo contrasts were observed at this low dosage level.

In their review of critical flicker frequency, Smith and Misiak (1976) refer to only one study of diazepam. It was found that flicker frequency was reduced in consequence of diazepam $10 \mathrm{mg}$.

Grundström et al. (1977) reported the responses of eight normal volunteers used in a cross-over design to examine the effect of different dosages of diazepam on critical flicker fusion frequency. It was found that the frequency threshold was lower for $22.5 \mathrm{mg}$ than for either 15 or $7.5 \mathrm{mg}$. The comparisons were in terms of the portion of the area under 6-h response curves.

Stitt et al. (1977) compared diazepam $5 \mathrm{mg}$ with placebo using a sample of 12 volunteers in a crossover procedure. Only two psychomotor tests were applied. One, a hidden word task, producing no changes but in cancellation there was a slight decrement that was significant at the 0.05 level.

Ghoneim \& Mewaldt (1977) compared diazepam $(0.3 \mathrm{mg} / \mathrm{kg}$ or about $20 \mathrm{mg}$ intravenously $)$ with placebo using groups of 10 volunteers. Using both recall and recognition procedures, it was found that material learned prior to the medication was unimpaired, but diazepam had a significant detracting effect on materials presented after the drug. Thus, their findings are consistent with those of previous reports to the effect that diazepam affects the storage and consolidation aspects of memory and learning, but may not affect the retrieval of material learned before administration of the drug.

The literature provides five reports of the effect of nitrazepam on the psychomotor behaviour of normal subjects. Malpas \& Joyce (1969) described a crossover study involving ten students. Their comparisons included placebo trials and nitrazepam 5 and $10 \mathrm{mg}$. Their testing battery was administered at 30,90 and 150 min after drug administration. Numerous signifi- 
cant contrasts were reported. Nitrazepam $10 \mathrm{mg}$ impaired the DSST performance at each testing. For the card sorting time score both 5 and $10 \mathrm{mg}$ showed significant increments relative to placebo at $90 \mathrm{~min}$ and at 150 minutes. The card sorting decision time was increased at these time periods for the $10 \mathrm{mg}$ dosage only. Nitrazepam tended also to increase the latency and shorten the duration of after-images for both the 5 and $10 \mathrm{mg}$ dosage levels. Thus, the detracting psychomotor effect of nitrazepam seems to be general.

The Bond \& Lader study (1972) used nitrazepam as an hypnotic with administration at bedtime the evening before the testing sequence. The design was a cross-over that involved tests of ten healthy volunteers at weekly intervals. Nitrazepam at 5 and $10 \mathrm{mg}$ was compared with placebo with respect to a series of psychomotor measures. It seems that nitrazepam had a retardant effect relative to placebo, particularly at the higher dosage level. Reaction time was increased, rate of tapping was decreased and rate of cancellation was reduced. The contrasts in card sorting were not significant but the DSST performance was impaired at both dosage levels. Other contrasts were consistent with the retardant effect of nitrazepam, but they did not attain significance.

Malpas (1972) also reported a study of ten healthy volunteers and compared nitrazepam 5 and $10 \mathrm{mg}$ with placebo in a cross-over design involving weekly assessments. Premedication assessments were made early afternoon, shortly before the drug was administered, and assessments were repeated frequently over a period of 160 minutes; $10 \mathrm{mg}$ was found to be detracting for speed of dealing cards at the $40 \mathrm{~min}$ assessment. The contrasts for the $5 \mathrm{mg}$ dosage were significant at the $70 \mathrm{~min}$ assessment. The DSST showed an impairment resulting from nitrazepam 10 $\mathrm{mg}$ at $30 \mathrm{~min}$ and from $5 \mathrm{mg}$ at about 50 minutes.

Peck et al. (1976) described psychomotor effects associated with the hypnotic use of nitrazepam with 12 healthy volunteers. In this cross-over study nitrazepam (5 and $10 \mathrm{mg}$ ) was compared with placebo. The medication was administered the previous evening and the tests were carried out the following day. In this cross-over design trials were repeated at weekly intervals. The tests included tapping, the DSST and an auditory vigilance procedure. In this, as in other hypnotic applications, there was no apparent premedication baseline. Only tapping was significantly lower for the $10 \mathrm{mg}$ dosage group than for the placebo group. The authors acknowledge that testing conducted after a shorter interval following medication might have revealed more general effects.

The most recent study on nitrazepam was contributed by Lahtinen et al. (1978). Thirty-four healthy female volunteers were involved in a comparison of nitrazepam 5 and $10 \mathrm{mg}$ with placebo. Medication was given late in the evening as an hypnotic, and psycho- motor testing was conducted the following morning. In this study, as in most others involving the hypnotic use of nitrazepam, no premedication baseline assessments were available. By reducing the interval between medication and psychomotor testing, numerous indications of impairment were shown. Relative to placebo, the $5 \mathrm{mg}$ dosage significantly detracted from the speed with which the subject could move beads or put caps on ball point pens. At the $10 \mathrm{mg}$ dosage these tasks, as well as pushing pencils through a hole and putting them in a box and moving drawing pins, required more time than when carried out under placebo.

There were two studies describing the psychomotor effects of flurazepam. Bond \& Lader (1973) compared flurazepam at 15 and $30 \mathrm{mg}$ levels with placebo. Eight healthy volunteers took part in this cross-over study that involved weekly assessments. The drug was hypnotically administered, late in the evening preceding the testing, and on the following day assessments were carried out at 1200, 1500 and 1800 . Seven psychomotor measures were applied, including auditory reaction time, visual reaction time, tapping, cancellation, card sorting, symbol copying and the DSST. Both symbol copying and the DSST performance were adversely affected relative to placebo. The statistical significance of these contrasts was presumably based on a split-plot analysis of variance. As no premedication measures were provided it is difficult to interpret the data with confidence.

Veldkamp et al. (1974) used 23 healthy volunteers to examine the psychomotor effects of the hypnotic use of flurazepam $30 \mathrm{mg}$ and placebo. The drug was administered at 2300 and testing began at 0830 the following day. No adverse effects were found for digit symbol substitution, card sorting or ocular convergence.

There were two medazepam studies also. Bernstein et al. (1967) compared medazepam $10 \mathrm{mg}$ with placebo in a cross-over involving 16 volunteers. Medazepam was associated with a smaller number of errors than placebo in the pursuit rotor performance. Under delayed auditory feedback, arithmetic, reading, counting and colour naming were compared, but the placebo contrasts were not significant.

Landauer et al. (1974) examined the psychomotor consequences of medazepam on the performance of healthy volunteers. Three groups of 12 men received medazepam 0,10 or $20 \mathrm{mg}$. The psychomotor tests included two driving simulators, a response timer, dot tracking and serial reaction time. No significant consequences of the medication were reported. Had pretreatment differences been controlled, it is possible that some significant contrasts might have been discernible.

Only one acceptable report was available for some drugs. In the study by Veldkamp et al. (1974) the effect of triazolam 0.5 and $1 \mathrm{mg}$ was compared with placebo. The hypnotic use of triazolam at both 0.5 and 
$1 \mathrm{mg}$ levels was found to impair DSST performance the morning following treatment. At both dosage levels triazolam adversely affected the card sorting time. The medications also had a detracting effect on ocular convergence.

Chlordesmethyldiazepam 1 and $2 \mathrm{mg}$ was compared with placebo by Zimmermann-Tansella et al. (1976). Eight healthy volunteers participated in a cross-over procedure. The procedure was designed to examine the hypnotic properties, and for this purpose medication was given at 2300 . The testing began about $12 \mathrm{~h}$ later. In this study, as in virtually all of the other hypnotic trials described in the present review, there were no premedication assessments, and no correction could be made for premedication individual or group differences. Thus, effects were examined in terms of placebo comparisons with no provision for initial bias. No significant differences were found in the various measures of reaction time, but card sorting was adversely affected by the $2 \mathrm{mg}$ dosage. DSST performance, digit copying, and performance on the Gibson Spiral Maze were unaffected. Cancellation was adversely affected but arithmetic and tapping were not. Thus, it seems that certain simple repetitive perceptual motor tasks were adversely affected in a dose-related manner $12 \mathrm{~h}$ after administration of this compound.

Hedges et al. (1971) used a sample of eight volunteers to compare lorazepam 5 and $10 \mathrm{mg}$ with placebo with respect to changes in critical flicker fusion frequency, cancellation, arithmetic and reaction time. Lorazepam was associated with significantly greater than placebo reductions in critical flicker fusion frequency, accuracy of cancellation, and increase in reaction time Because of the way in which the significance analyses were carried out and reported, the reader cannot be certain that the specific contrasts between lorazepam and placebo were significant.

A sample of 60 volunteers was assigned at random by Wittenborn et al. (1976) to placebo or prazepam $30 \mathrm{mg}$ administered in $10-\mathrm{mg}$ units throughout the course of the day. Drug effects were examined in terms of changes in pursuit rotor scores, cancellation, reaction time and time estimation, that is, the duration of the interval produced by the subjects in response to a request for an 8-s interval; no standard for comparison was allowed. Prazepam reduced a natural tendency to overestimate the amount of time required to generate an interval.

In a recent report (not included in the summary tables), Wittenborn et al. (1979) described a study of the psychomotor responses of normal student volunteers. Thirty were assigned to placebo and 30 received clobazam $30 \mathrm{mg}$ administered in $10-\mathrm{mg}$ units over the course of a day. The assessments made before the initial medication and at hourly intervals thereafter included reaction time. DSST, arithmetic, perceptual reversal, balance beam, a time estimation procedure in which the subject was asked to produce a time interval without benefit of a standard, and a vigilance testing procedure. Most of the clobazam-placebo contrasts were not significant. There was a significant and increasing tendency for the clobazam subjects to step off the balance beam less often than the placebo subjects. It was also found that the length of error sequences in the vigilance test was shorter for the clobazam subjects than for the placebo subjects. Thus, clobazam was not found to involve the impairments that seem to be a general feature of psychomotor response to benzodiazepines. The positive effect of clobazam (relatively few missteps on the balance beam and relatively short error sequences) justify confirmation and exploration. These suggest that clobazam may involve motivational enhancements.

\section{Conclusions}

This review of the pattern of findings showed no general contrasts in the qualitative effects of the various benzodiazepines, and because of the diversity of the psychomotor tests used, the overall implications of these findings for benzodiazepines in general are difficult to state. In order to summarize the psychomotor effects of benzodiazepines, an attempt was made to classify the various tests with respect to what was judged to be the essential nature of the operation examined. As would be expected, however, some of the tests were unique not only in the sense that they were used in only one investigation but that they could not be confidently subsumed under any class or group. Some investigators used several tests of a given class, and under such circumstances the implications of the tests tended to confirm each other. Such overlapping, if not multiple testing of a function within a study, was considered to be but one application in generating the present summary statement of psychomotor effects.

No published investigations included in the present review showed the benzodiazepines to enhance behaviour, and the detracting effects were doserelated. As virtually all effects were detracting, the task of summarizing became essentially one of identifying those psychomotor functions that were impaired by a particular drug in each study. The relative incidence of impairment for a given psychomotor function may be stated as a ratio between the number of studies showing impairment in a given function and the number of studies that tested the respective function.

The 16 most commonly tested psychomotor functions are included in Tables 1 and 2. The listings include the number of instances in which each was applied, as well as the number of instances in which performance was adversely affected. Reaction time and the DSST were the most commonly used assessments, having been applied in twelve and ten separate instances, respectively. The frequency with which the 
Table 1 Psychomotor tests for benzodiazepine effects (most discriminating)

$\begin{array}{lcc}\text { Assessments } & \text { Applications * Discriminations } \\ & & \\ \text { Critical flicker fusion } & 5 & 5 \\ \quad \text { frequency } & 4 & 4 \\ \text { Learning and memory } & 2 & 2 \\ \text { Manipulative } & 2 & 2 \\ \text { Time estimation } & 10 & 6 \\ \text { DSST } & 9 & 4 \\ \text { Cancellation } & 7 & 3 \\ \text { Card sorting } & 8 & 3 \\ \text { Tapping } & \\ \text { * Different dosages of the same drug within a study are } \\ \text { not considered as separate applications. 27 studies } \\ \text { were included. }\end{array}$

Table 2 Psychomotor tests for benzodiazepine effects (least discriminating)

\section{Assessments}

\section{Applications* Discriminations}

Spatial

Auditory perception

Delayed feedback

Reaction time

Visual coordination

Arithmetic

Pursuit rotor

Symbol copying

$\begin{array}{rl}3 & 0 \\ 3 & 0 \\ 3 & 0 \\ 12 & 3 \dagger \\ 4 & 1 \dagger \\ 4 & 1 \\ 6 & 2 \\ 3 & 1\end{array}$

- Different dosages of the same drug within a study are not considered as separate applications. 27 studies were included.

tOne instance of improvement.

tests were used by the investigator bore little relationship to their discriminating sensitivity. For example, reaction time which was used in twelve instances was discriminating in only three instances, whereas critical flicker fusion frequency applied in five instances was invariably discriminating as was

\section{References}

BERNSTEIN, M.E., HUGHES, F.W. \& FORNEY, R.B. (1967) The influence of a new chlordiazepoxide analogue on human mental and motor performance. J. clin. Pharmac., 7, 330-335.

BETTS, T.A., CLAYTON, A.B. \& MACKAY, G.M. (1972). Effects of four commonly-used tranquillizers on lowspeed driving performance tests. Br. med. J., 4, 580-584.

BOND, A.J. \& LADER, M.H. (1972). Residual effects of hypnotics. Psychopharmacologia, Berlin, 25, 117-132.

BOND, A.J. \& LADER, M.H. (1973). The residual effects of flurazepam. Psychopharmacologia, Berlin, 32, 223-235.

CLARKE, P.R.F., ECCERSLEY, P.S., FRISBY, J.P. \& THORNTON, J.A. (1970). The amnesic effect of diazepam (Valium). Brit. J. Anaesth., 42, 690-697. memory which was applied in four instances.

In general, it seems that the most sensitive functions were critical flicker fusion frequency, memory, DSST, cancellation and card sorting. Manual tests involving rote manipulation and time estimation by means of producing a temporal interval were applied in only two instances each, but were sensitive in both applications. Functions that seemed to be relatively insensitive were complex visual motor coordination, visual-spatial performance, auditory perception, performance under delayed auditory feedback, and memory for material preceding the medication. Some of the functions which were only rarely applied yielded provocative findings. For example, simulated driving was not affected but actual driving was impaired.

It seems that the benzodiazepines have little effect on such established faculties as visual-spatial, perceptual, verbal and possibly arithmetical, but the acquisition of new material as represented by the memory functions and the orientation to digit symbol association were sensitive to these drugs. It seems, moreover, that speed of repetitive movements as represented by cancellation, the speed of manipulation tests, card sorting and tapping are relatively sensitive.

On the basis of the presently available body of wellcontrolled research reports based on reaction of normal volunteers during their initial day of medication, three general statements may be offered: (1) the speed with which simple acts of a repetitive nature are performed may be impaired by benzodiazepines; (2) learning and immediate memory will also be impaired; (3) there is relatively little indication that well established higher mental faculties are adversely involved.

The essential organization and broad implications of the benzodiazepine impairments are not illuminated by the present descriptive inquiries. Conceivably the effects are mediated by affective channels, and the changes reported here could be motivational in their meaning. Certainly the association between the impairment resulting from benzodiazepines and the reduction of critical flicker fusion frequency is provocative and should be examined intensively.

GHONEIM, M.M. \& MEWALDT, S.P. (1975). Effects of diazepam and scopolamine on storage, retrieval and organizational processes in memory. Psychopharmacologia, Berlin, 44, 257-262.

GHONEIM, M.M. \& MEWALDT, S.P. (1977). Studies on human memory: the interactions of diazepam, scopolamine and physostigmine. Psychopharmacologia, Berlin, 52, 1-6.

GHONEIM, M.M., MEWALDT, S.P. \& THATCHER, J.W (1975). The effect of diazepam and fentanyl on mental, psychomotor and electroencephalographic functions and their rate of recovery. Psychopharmacologia, Berlin, 44, 61-66. 
GRUNDSTRÖM, R., HOLMBERG, G., LEDERMANN, H. \& LIVSTEDT, B. (1977). Sedative properties of doxepin in comparison with diazepam. Psychopharmacologia, Berlin, 54, 165-169.

HEDGES, A., TURNER, P. \& HARRY, T.V.A. (1971). Preliminary studies on the central effects of lorazepam, a new benzodiazepine. J. clin. Pharmac., 11, 423-427.

HOLMBERG, G. \& WILLIAM-OLLSON, U. (1963). The effect of benzquinamide, in comparison with chlordiazepoxide and placebo, on performance in some psychological tests. Psychopharmacologia, Berlin, 4, 402-417.

HUGHES, F.W., FORNEY, R.B. \& RICHARDS, A.B. (1965). Comparative effect in human subjects of chlordiazepoxide, diazepam and placebo on mental and physical performance. Clin. Pharmac. Ther., 6, 139-145.

IDESTRÖM, C-M. \& CADENIUS, B. (1963). Chlordiazepoxide, dipiperon and amobarbital. Psychopharmacologia, Berlin, 4, 235-246.

JÄÄTTELÄ, A., MÄNNISTÖ, PAATERO, H. \& TUOMISTO, J. (1971). The effects of diazepam or diphenhydramine on healthy human subjects. Psychopharmacologia, Berlin, 21, 202-211.

KARNIOL, I.G., DALTON, J. \& LADER, M. (1976). Comparative psychotropic effects of trazodone, imipramine and diazepam in normal subjects. Curr. ther. Res., 20, 337-348.

KLEINKNECHT, R.A. \& DONALDSON, D. (1975). A review of the effects of diazepam on cognitive psychomotor performance. J. Nerv. Ment. Dis., 161, 399-411.

LAHTINEN, U., LAHTINEN, A. \& PEKKOLA, P. (1978). The effect of nitrazepam on manual skill, grip strength and reaction time with special reference to subjective evaluation of effects on sleep. Acta Pharmac. Toxic., 42, 130-134.

LANDAUER, A.A., POCOCK, D.A. \& PROTT, F.W. (1974). The effect of medazepam and alcohol on cognitive and motor skills used in car driving. Psychopharmacologia, Berlin, 37, 159-168.

MALPAS, A. (1972). Subjective and objective effects of nitrazepam and amylobarbitone sodium in normal human beings. Psychopharmacologia, Berlin, 27, 373378.

MALPAS, A. \& JOYCE, C.R.B. (1969). Effects of nitrazepam, amylobarbitone and placebo on some perceptual, motor and cognitive tasks in normal subjects. Psychopharmacologia, Berlin, 14, 167-177.
MCNAIR, D.M. (1973). Antianxiety drugs and human performance. Arch. gen. Psychiat., 29, 611-617.

MASUDA, M. \& BAKKER, C.B. (1966). Personality, catecholamine metabolites and psychophysiological response to diazepam. J. Psychiatr. Res., 4, 221-234.

PECK, A.W., ADAMS, R., BYE, C. \& WILKINSON, R.T. (1976). Residual effects of hypnotic drugs: evidence for individual differences on vigilance. Psychopharmacologia, Berlin, 47, 213-216.

SMITH, J.M. \& MISIAK, H. (1976). Critical flicker frequency (CFF) and psychotropic drugs in normal human subjects - a review. Psychopharmacology, 47, 175-182.

STITT, F.W., LATOUR, R. \& FRANE, J.W. (1977). A clinical study of naproxen-diazepam drug interaction on tests of mood and attention. Curr. ther. Res., 21, 149-156.

VELDKAMP, W., STRAW, R.N., METZLER, C.M. \& DEMISSIANOS, H.V. (1974). Efficacy and residual effect evaluation of a new hypnotic, triazolam. J. clin. Pharmac., 14, 102-111.

WITTENBORN, J.R. (1978). Behavioral Toxicity in Normal Humans as a Model for Assessing Behavioral Toxicity in Patients. In Psychopharmacology: A Generation of Progress. Ed. Lipton, M.A., Di Mascio, A. \& Killam, K.F. New York: Raven.

WITTENBORN, J.R., FLAHERTY, C.F., MCGOUGH, W.E., BOSSANGE, K.A. \& NASH, R.J. (1976). A comparison of the effect of imipramine, nomifensine and placebo on the psychomotor performance of normal males. Psychopharmacology, 51, 85-90.

WITTENBORN, J.R., FLAHERTY, C.F., HAMILTON, L.W., SCHIFFMAN, H.R. \& McGOUGH, W.E. (1976). The effect of minor tranquilizers on psychomotor performance. Psychopharmacology, 47, 281-286.

WITTENBORN, J.R., FLAHERTY, C.F., McGOUGH, W.E. \& NASH, R.J. (1979). Psychomotor changes during the initial day of benzodiazepine medication. Br. J. clin. Pharmac., 7, 69S-76S.

ZIMMERMAN-TANSELLA, C., TANSELLA, M. \& LADER, M. (1976). The effects of chlordesmethyldiazepam on behavioral performance and subjective judgment in normal subjects. J. clin. Pharmacol., 16, 481-488. 